\title{
Evaluation of stress effects of copper oxide nanoparticles in Brassica napus L. seedlings
}

\author{
Prakash M. Gopalakrishnan Nair ${ }^{1}$ IIl Min Chung ${ }^{1}$
}

Received: 31 August 2016/Accepted: 22 August 2017/Published online: 30 August 2017

(C) Springer-Verlag GmbH Germany 2017

\begin{abstract}
Rapid growth of nanotechnology has enabled the production and use of engineered nanoparticles (ENPs) in several industries as well as in agriculture areas. This has raised ecotoxicological concerns due to the release of ENPs to the environment. In the present study, we investigated the effects of interactions of copper oxide nanoparticles (CuO NPs) on physiological, biochemical, and molecular indices in seedlings of an important oil seed crop Brassica napus $\mathrm{L}$. The seedlings were treated with $0,20,50,100$, 200, 400, and $500 \mathrm{mg} / \mathrm{L}$ of CuO NPs for 14 days in halfstrength semi-solid Murashige and Skoog medium. The $\mathrm{CuO}$ NPs treatment significantly reduced shoot and root growth as well as plant biomass. Shortening and thickening of primary and lateral roots and inhibition of lateral root growth was observed at higher concentrations. An increase in reactive oxygen species generation, and malondialdehyde accumulation was observed. Histochemical staining of roots with propidium iodide and aniline blue indicated cell death and callose formation in roots. Transcriptional modulation of genes related to oxidative stress viz. $\mathrm{CuZn}$ superoxide dismutase, catalase, and ascorbate peroxidase was observed. Element content analysis showed an increase in $\mathrm{Cu}$ content and decrease in $\mathrm{Fe}, \mathrm{Mn}$, and $\mathrm{Zn}$ contents. Overall, exposure to $\mathrm{CuO} \mathrm{NPs}$ caused oxidative
\end{abstract}

Electronic supplementary material The online version of this article (doi:10.1007/s13205-017-0929-9) contains supplementary material, which is available to authorized users.

Prakash M. Gopalakrishnan Nair

pmgnair@gmail.com

1 Department of Applied Bioscience, College of Life and Environmental Sciences, Konkuk University, 120 Neungdong-ro, Gwangjin-gu, Seoul 05029, South Korea injury, cell death, callose formation, and decreased the micro nutrient contents in B. napus seedlings.

Keywords Brassica napus - Copper oxide nanoparticles · Root system · Oxidative stress · Callose formation ·

Microelements

\section{Introduction}

The rapid growth of nanotechnology enhanced the use of engineered nanoparticles (ENPs) in various products. This has raised concerns about the release of ENPs from these products, thereby causing concerns due to the possibility of contamination of natural as well as agricultural ecosystems (Navarro et al. 2008). Previous studies have shown that the environmental pollution of ENPs could occur as a result of their release from different sources such as industries, waste treatment plants, and also by their direct use for agricultural purposes. For instance, the direct application of sewage sludge in agricultural soils for nutrient supply may also be contaminated with ENPs (Gardea-Torresdey et al. 2014). This will result in the accumulation of ENPs in agricultural soils as well as their entry into plants. The ENPs can also enter into food chains as a result of their widespread use for delivery of fertilizers and nanopesticides (Das et al. 2009; Wang et al. 2012).

Copper $(\mathrm{Cu})$ is a microelement required for the proper growth, development, and survival of plants. In agricultural fields, excess accumulation of $\mathrm{Cu}$ can occur due to mining operations, sewage sludge disposal, and the use of poor quality water for irrigation purposes (Yruela 2009). Exposure to excess $\mathrm{Cu}$ leads to growth retardation as well as oxidative stress injuries in plants (Schützendübel and 
Polle 2002; Yruela 2005). Due to their physico-chemical properties, copper oxide nanoparticles (CuO NPs) were used in bioactive coatings, antimicrobial and antifouling paints, air and liquid filtration units, lubricant oils, textiles, and superconducting materials (http://www. nanotechproject.org). However, studies have shown the release of $\mathrm{CuO}$ NPs to the environment from these products could cause ecotoxicological threats owing to their toxic effects on plants (Wang et al. 2012).

Earlier investigations have proved that the toxic responses of metals varies between different types of plants and even the different cultivars of the same crop also showed differential sensitivity to metals (Ali et al. 2014). For instance, differential sensitivity to chromium $(\mathrm{Cr})$ among different genotypes of the same species has been reported (Shahandeh and Hossner 2002). Gill et al. (2014) also reported genotypic variation in response to $\mathrm{Cr}$ toxicity in four oilseed rape cultivars. According to a study by Ali et al. (2014), the stress responses of two cultivars of $B$. napus exposed to same concentrations of $\mathrm{Cd}$ showed different responses. Feigl et al. (2013) reported that when exposed to $\mathrm{Cu}$ excess the morphological adaptation strategy, especially, the root system development in $B$. juncea and $B$. napus showed differences. In a previous study, we observed toxic responses in $B$. juncea seedlings exposed to CuO NPs (Nair and Chung 2015). In the present study, to check the species specific effects, using the same concentrations of $\mathrm{CuO}$ NPs and growth conditions as described in the previous study, the physiological, biochemical, and molecular level effects of $\mathrm{CuO}$ NPs were investigated in $B$. napus seedlings.

\section{Materials and methods}

\section{Plant culture and exposure}

The commercially available $\mathrm{CuO}$ NPs purchased from the Sigma-Aldrich (St. Louis, MO, USA) was used in the present study. The size distribution and morphological analysis of CuO NPs was carried out using Dynamic Light Scattering spectrometer (DLS-7000, Otsuka Electronics Co., Inc., Osaka, Japan) and transmission electron microscopic (TEM; Carl Zeiss, Oberkochen and Baden-Württemberg, Germany) analysis. The TEM analysis was conducted by drop coating of $\mathrm{CuO}$ NPs suspension on a 400-mesh carbon-coated copper grid (Tedpella Inc., Reading, USA). The grids were dried overnight and imaged using TEM.

Different concentrations of CuO NPs $(0,20,50,100$, 200,400 , and $500 \mathrm{mg} / \mathrm{L}$ ) were mixed by vortexing with autoclaved semi-solid half-strength Murashige and Skoog medium (100 mL; Duchefa Biochemie, Haarlem, The
Netherlands). One hundred milliliter of medium was poured into each of the culture vessels $(120 \times 80 \mathrm{~mm}$; Phytohealth, SPL Life Sciences, Gyeonggi-do, South Korea) and solidified by keeping at $4{ }^{\circ} \mathrm{C}$ for $5 \mathrm{~min}$ for avoiding precipitation of $\mathrm{CuO}$ NPs.

The seeds were disinfected with $10 \%(\mathrm{v} / \mathrm{v})$ sodium hypochlorite solution for $20 \mathrm{~min}$ and thereafter washed five times with autoclaved deionized water. The seeds were germinated by keeping under dark conditions on wet Whatman \#1 paper for $48 \mathrm{~h}$. In each vessel, 10 germinated seeds were placed. Four replications were maintained for each of the treatments and the study was repeated thrice. The seedlings were incubated in a growth chamber (Hanbaek Scientific Co., Gyeonggi-do, South Korea) under 16:8 h of light:dark period at $26 \pm 2{ }^{\circ} \mathrm{C}$ for 14 days.

\section{Morphological measurements}

For growth measurements, the seedlings were removed from the growth medium, washed several times with autoclaved deionized water, and blotted dry on Whatman \#1 paper. The shoot and root lengths were determined using a scale and the fresh weights (FW) were determined with the help of an electronic balance (Mettler Toledo, Switzerland). Morphological analysis of the roots was conducted using a stereomicroscope (Nikon, Japan) and photographed with a digital camera (Canon, Japan).

\section{Analysis of microelement content}

Samples collected from the control as well as seedlings grown in the presence of low $(50 \mathrm{mg} / \mathrm{L})$, medium $(200 \mathrm{mg} /$ $\mathrm{L})$, and high $(400 \mathrm{mg} / \mathrm{L})$ concentrations of $\mathrm{CuO}$ NPs were dried at $70{ }^{\circ} \mathrm{C}$ for $72 \mathrm{~h}$ in a dry air oven. The dried samples (20 mg) were digested with concentrated $\mathrm{HNO}_{3}$ at $115^{\circ} \mathrm{C}$ for $12 \mathrm{~h}$ using a dry bath (JBI-01; JMC R\&D Inc., Daejeon, South Korea). The samples were made up to $25 \mathrm{~mL}$ with autoclaved deionized water after digestion. The samples were filtered through $0.2 \mu \mathrm{m}$ nylon filters (Chromedisc ${ }^{\circledR}$ syringe filter, Seoul, South Korea). The microelement content viz. $\mathrm{Cu}, \mathrm{Fe}, \mathrm{Zn}$, and $\mathrm{Mn}$ analysis was done at NICEM (National Instrumentation Center for Environmental Management, Seoul National University, Seoul, Korea) using inductively coupled plasma emission spectrometer (ICP-730ES; Varian, USA).

\section{Analysis of hydrogen peroxide content and lipid peroxidation}

The hydrogen peroxide $\left(\mathrm{H}_{2} \mathrm{O}_{2}\right)$ content in shoots and roots was analyzed using the protocol of Brennan and Frenkel (1977). The samples (100 mg, Fresh weight; FW) were homogenized in $4 \mathrm{~mL}$ cold acetone and filtered through 
Whatman filter paper \#1. To the filtrate $(2 \mathrm{~mL}), 1 \mathrm{~mL}$ of $20 \%$ titanium chloride in concentrated $\mathrm{HCl}(\mathrm{v} / \mathrm{v})$ was added. One microliter of concentrated ammonia solution $(6 \mathrm{~N})$ was added to the mixture and centrifuged at $5000 \mathrm{~g}$ for $30 \mathrm{~min}$. The precipitate was collected and redissolved in $1 \mathrm{~mol} / \mathrm{L} \mathrm{H}_{2} \mathrm{SO}_{4}$, washed, and dissolved in water. The $\mathrm{H}_{2} \mathrm{O}_{2}$ content was measured at $415 \mathrm{~nm}$ using UV-VIS spectrophotometer (Optizen, South Korea) and was quantified using a standard curve generated using known concentrations of $\mathrm{H}_{2} \mathrm{O}_{2}$.

The lipid peroxidation level was determined as per Heath and Packer's (1968) procedure. After homogenizing the samples (100 mg each; FW) in $5 \mathrm{~mL}$ of $0.1 \%(\mathrm{w} / \mathrm{v})$ trichloroacetic acid solution, they were centrifuged at $7000 \mathrm{~g}$ for $10 \mathrm{~min}$ at room temperature. Two milliliter of $0.67 \%(\mathrm{w} / \mathrm{v})$ thiobarbituric acid was mixed with $2 \mathrm{~mL}$ of supernatant and boiled at $95{ }^{\circ} \mathrm{C}$ for $30 \mathrm{~min}$. The samples were cooled immediately and centrifuged at $6000 \mathrm{~g}$ for $5 \mathrm{~min}$ and absorbance was measured at 532 and $600 \mathrm{~nm}$ using a UV-VIS spectrophotometer (Optizen UV/VIS spectrophotometer, South Korea). The malondialdehyde (MDA) concentration was calculated using extinction coefficient $155 \mathrm{mmol}^{-1} \mathrm{~cm}^{-1}$.

\section{Microscopic analysis}

ROS generation in shoots was determined by treating with $3^{\prime} 3^{\prime}$-diaminobenzidine (DAB) (Thordal-Christensen et al. 1997). The fluorescent probe $3^{\prime}$-( $p$-hydroxyphenyl) fluorescein (HPF) (Invitrogen, USA) was used to check ROS generation in roots as described by Kwasniewski et al. (2013). Callose formation in roots was determined by treating with aniline blue for $1 \mathrm{~h}$ under dark conditions (Horst et al. 1997). The treated roots were rinsed with $0.1 \mathrm{M} \mathrm{K}_{3} \mathrm{PO}_{4}(\mathrm{pH}$ ) before imaging. Root cell death was determined using propidium iodide (PI) treatment as described by Kwon et al. (2013). The root tips were stained with $5 \mathrm{mg} / \mathrm{L}$ PI (after dissolving in water) in a watch glass. The DAB stained stem samples were photographed with Canon Power Shot (Canon, Japan) camera and the HPF, aniline blue, and PI-treated roots were imaged and analyzed with fluorescent microscope and associated software (BX61-32 FDIC, Olympus, Japan).

\section{Gene expression analysis}

One microgram from the total RNA isolated using the RNA extraction and clean up kit (Qiagen, Valencia, CA, USA) was used for the synthesis of cDNA. The cDNA was synthesized using QuantiTect ${ }^{\circledR}$ reverse transcription kit (Qiagen). The list of primers for the CuZnSOD, CAT, APX, and $A C T$ (internal control) genes is given in Supplementary Table 1. Gene expression analysis was carried out using the Chromo-4TM thermocycler (Bio-Rad, USA). The reaction mix included $1 \mu \mathrm{L}$ of cDNA, $0.2 \mu \mathrm{M}$ forward and reverse primers and $10 \mu \mathrm{L}$ of $2 \mathrm{X}$ IQ SYBR Green Super Mix (Bio-Rad) and made up to $20 \mu \mathrm{L}$ using deionized water. The reaction was conducted with an initial denaturation at $95{ }^{\circ} \mathrm{C}$ for $7 \mathrm{~min}$ followed by 40 cycles of $95{ }^{\circ} \mathrm{C}$ for $15 \mathrm{~s}, 56{ }^{\circ} \mathrm{C}$ for $30 \mathrm{~s}$, and $72{ }^{\circ} \mathrm{C}$ for $30 \mathrm{~s}$. After that a melting curve analysis was conducted. The relative expression level of different genes as compared to the internal control was calculated using the Bio-Rad gene expression analysis software.

\section{Statistical analysis}

Data were analyzed using one-way analysis of variance (ANOVA) with SPSS 12.0 KO (SPSS Inc., Chicago, IL, USA) programme. Treatment differences as compared to the controls were examined with Dunnett's post hoc test and significant differences were determined at $p<0.05$ probability level.

\section{Results}

\section{Characterization of CuO NPs}

TEM analysis revealed different morphologies viz. near spherical, rectangular, and rod shaped. Size distribution analysis using dynamic light scattering spectrometer showed that the $\mathrm{CuO}$ NPs were $10-50 \mathrm{~nm}$ in size with majority of them being $30 \mathrm{~nm}$ (Supplementary Fig. 1A, B).

\section{Morphological observations}

The growth of the seedling showed reduction after exposure to increasing concentrations of $\mathrm{CuO}$ NPs (Fig. 1a). Exposure to $\mathrm{CuO}$ NPs changed the root architecture as evidenced by thickening and reduction of primary and lateral roots. Inhibition of lateral root formation was observed in seedlings treated with above $20 \mathrm{mg} / \mathrm{L}$ of $\mathrm{CuO}$ NPs (Fig. 1b). Significant reduction in length and fresh weights of shoots and roots occurred with increasing concentrations of $\mathrm{CuO}$ NPs exposure (Fig. 1c, d).

\section{Analysis of microelements}

The $\mathrm{Cu}$ content was significantly increased in shoots and roots of $B$. napus seedlings. In comparison with shoots, higher amount of $\mathrm{Cu}$ accumulation was detected in roots (Fig. 2a). However, significant decrease in $\mathrm{Zn}, \mathrm{Fe}$, and Mn contents occurred in $\mathrm{CuO}$ NPs exposed seedlings as compared to the controls (Fig. 2b-d). 

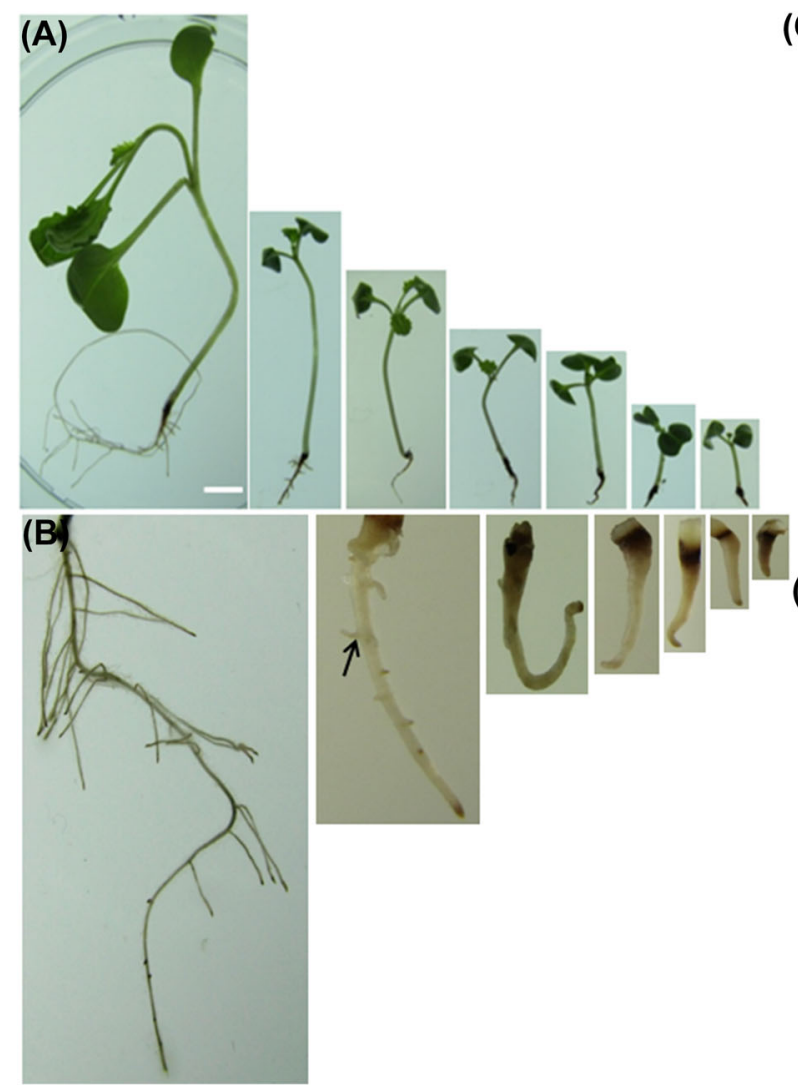

Fig. 1 a Brassica napus seedlings exposed to different concentrations of $\mathrm{CuO} \mathrm{NPs}$ for 14 days. b Root morphology of B. napus seedlings treated with different concentrations of $\mathrm{CuO}$ NPs for 14 days. (From left to right: control and seedlings grown in the presence of $20,50,100,200,400$, and $500 \mathrm{mg} / \mathrm{L}$ of $\mathrm{CuO} \mathrm{NPs}$,

\section{Hydrogen peroxide and lipid peroxidation}

The $\mathrm{H}_{2} \mathrm{O}_{2}$ content did not change significantly in shoots after exposure to 20 and $50 \mathrm{mg} / \mathrm{L}$ of $\mathrm{CuO} \mathrm{NPs}$, but it was significantly increased in shoots upon exposure to 100, 200, 400 , and $500 \mathrm{mg} / \mathrm{L}$ of $\mathrm{CuO}$ NPs (Fig. 3a). In roots, treatment with $20 \mathrm{mg} / \mathrm{L}$ of $\mathrm{CuO}$ NPs did not result in any significant change in $\mathrm{H}_{2} \mathrm{O}_{2}$ generation. However, the $\mathrm{H}_{2} \mathrm{O}_{2}$ content significantly increased when treated with 50, 100, 200, 400, and $500 \mathrm{mg} / \mathrm{L}$ of CuO NPs (Fig. 3a). Except for 20 and $50 \mathrm{mg} / \mathrm{L}$ of $\mathrm{CuO}$ NPs exposure, the lipid peroxidation levels showed significant increase in shoots after exposure to all other concentrations (Fig. 3b). In roots, except for $20 \mathrm{mg} / \mathrm{L}$, the lipid peroxidation level significantly increased after treatment with all other concentrations of CuO NPs (Fig. 3b).

\section{Microscopic analysis}

A gradual increase in $\mathrm{H}_{2} \mathrm{O}_{2}$ generation was observed in stems as indicated an increase in brown coloration after treatment with DAB stain (Fig. 4a). In roots, HPF
(C)
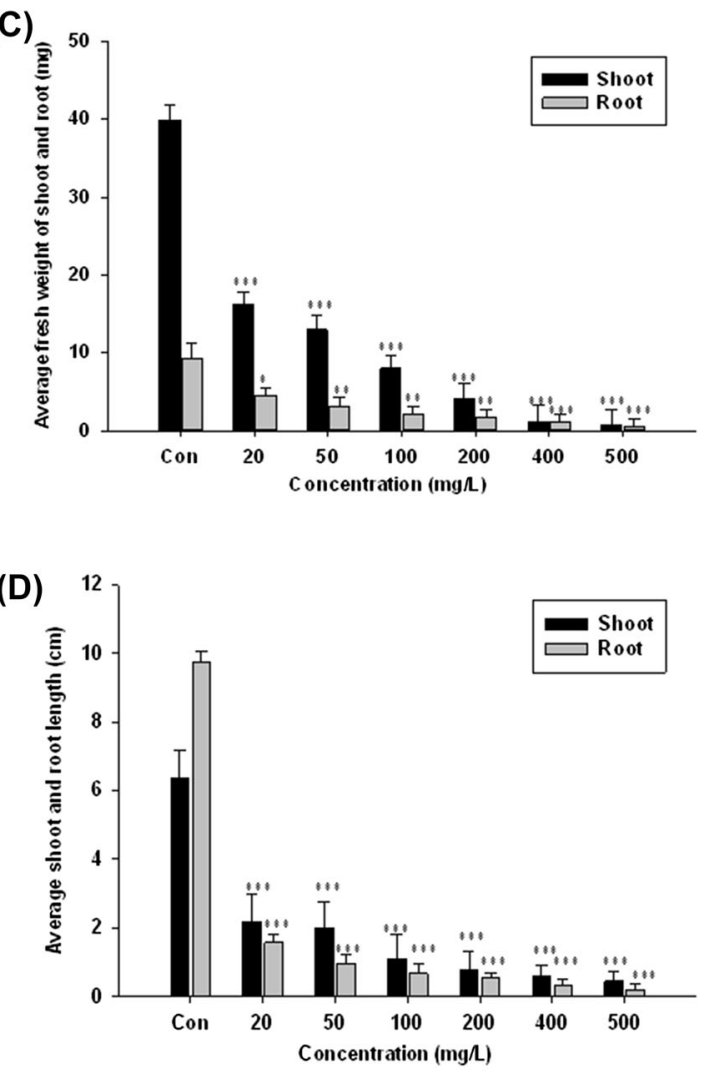

respectively). Arrow mark indicates lateral root. Scale bar indicate $1 \mathrm{~cm}$. c Average shoot and root length and $\mathbf{d}$ fresh weight of $B$. napus seedlings. Data are mean $\pm \mathrm{SE}$ of three replications and asterisks indicate significant difference at $* p<0.05, * * p<0.01$, and $* * * p<0.001$ level

treatment indicated an increase in ROS generation as indicated by an increase in fluorescence levels as a result of exposure to increasing concentrations of $\mathrm{CuO}$ NPs. The HPF fluorescence level was high at the root tips (Fig. 4b). Exposure to various concentrations of $\mathrm{CuO}$ NPs resulted in a concentration dependant increase in callose formation in roots (Fig. 4c). Examination of root cell viability using PI stain indicated cell death, in the root tips of seedlings exposed to $100-500 \mathrm{mg} / \mathrm{L}$ of $\mathrm{CuO}$ NPs (Fig. 4d).

\section{Gene expression}

The relative expression of $C U Z n S O D$ did not show significant change in shoots of $B$. napus seedlings grown in the presence of 20,50 , and $100 \mathrm{mg} / \mathrm{L}$ of $\mathrm{CuO} \mathrm{NPs}$ (Fig. 5a). However, the CuZnSOD gene expression significantly increased as a result of treatment with 200, 400, and $500 \mathrm{mg} / \mathrm{L}$ of $\mathrm{CuO}$ NPs (Fig. 5a). In roots, the expression of $\mathrm{CuZnSOD}$ gene was significantly increased when grown in the presence of 200,400 , and $500 \mathrm{mg} / \mathrm{L}$ of $\mathrm{CuO}$ NPs (Fig. 5a). In shoots of B. napus seedlings, the 

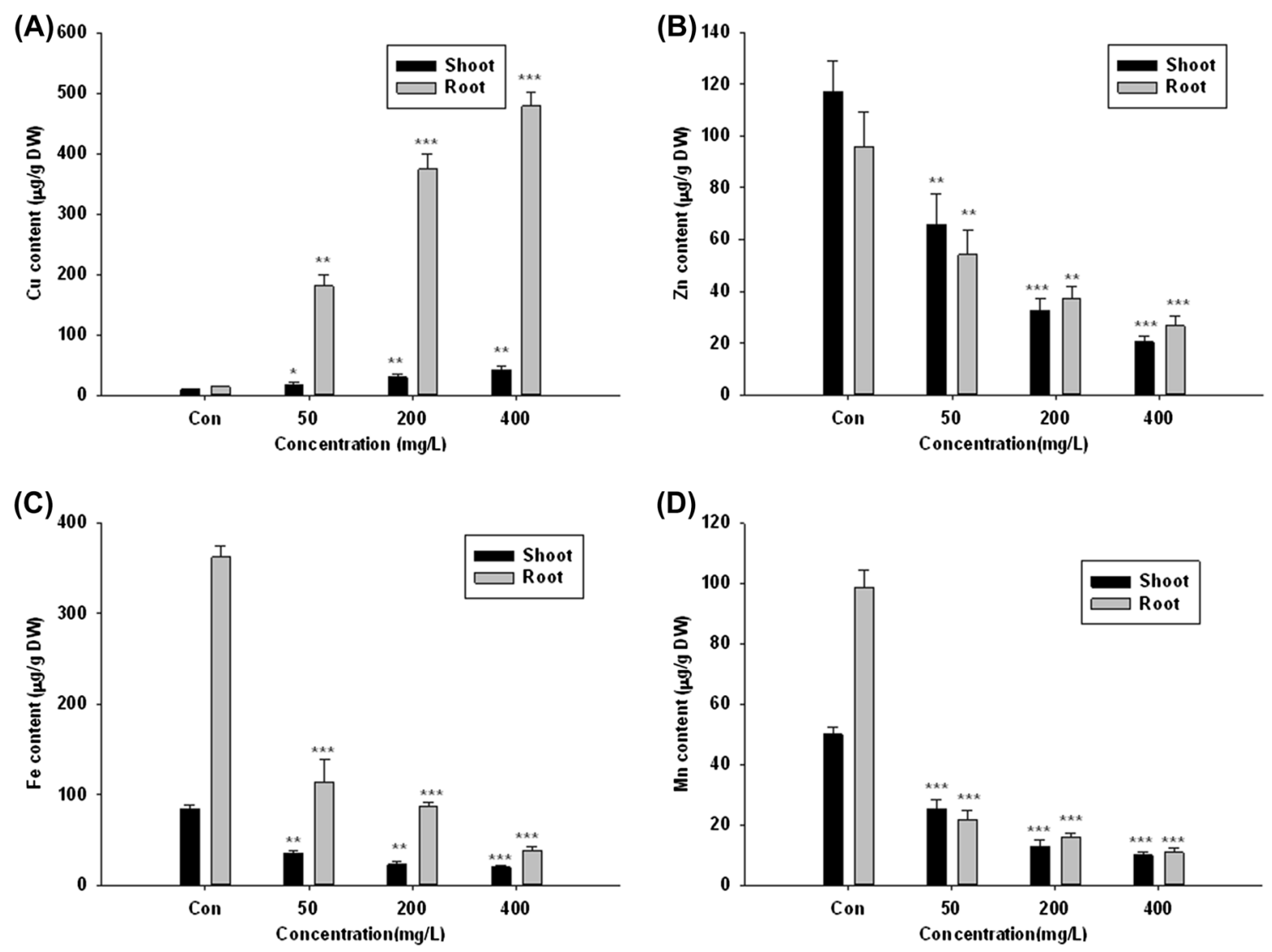

Fig. 2 Effects of 50, 200, and $400 \mathrm{mg} / \mathrm{L}$ of copper oxide nanoparticles on microelement $\mathbf{a ~} \mathrm{Cu}, \mathbf{b} \mathrm{Zn}, \mathbf{c} \mathrm{Fe}$, and $\mathbf{d} \mathrm{Mn}$ content in B. napus L. seedlings. Data are mean $\pm \mathrm{SE}$ of three replications and significant

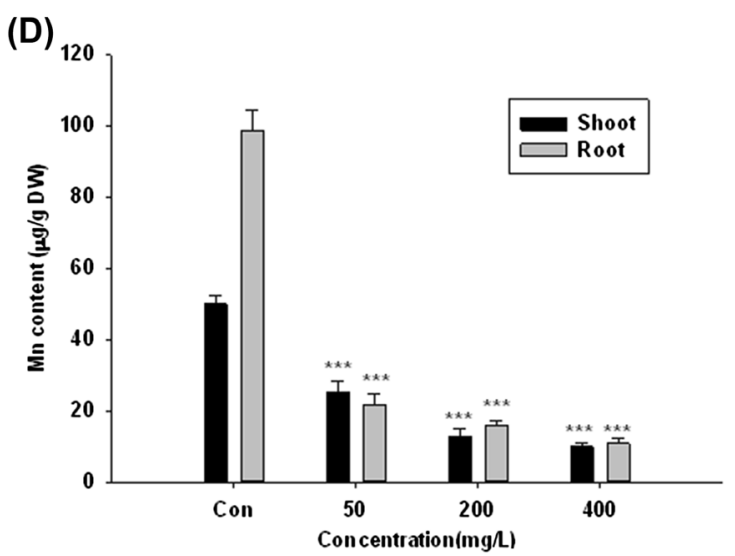

differences were indicated with asterisks at $* p<0.05, * * p<0.01$, and $* * * p<0.001$ level
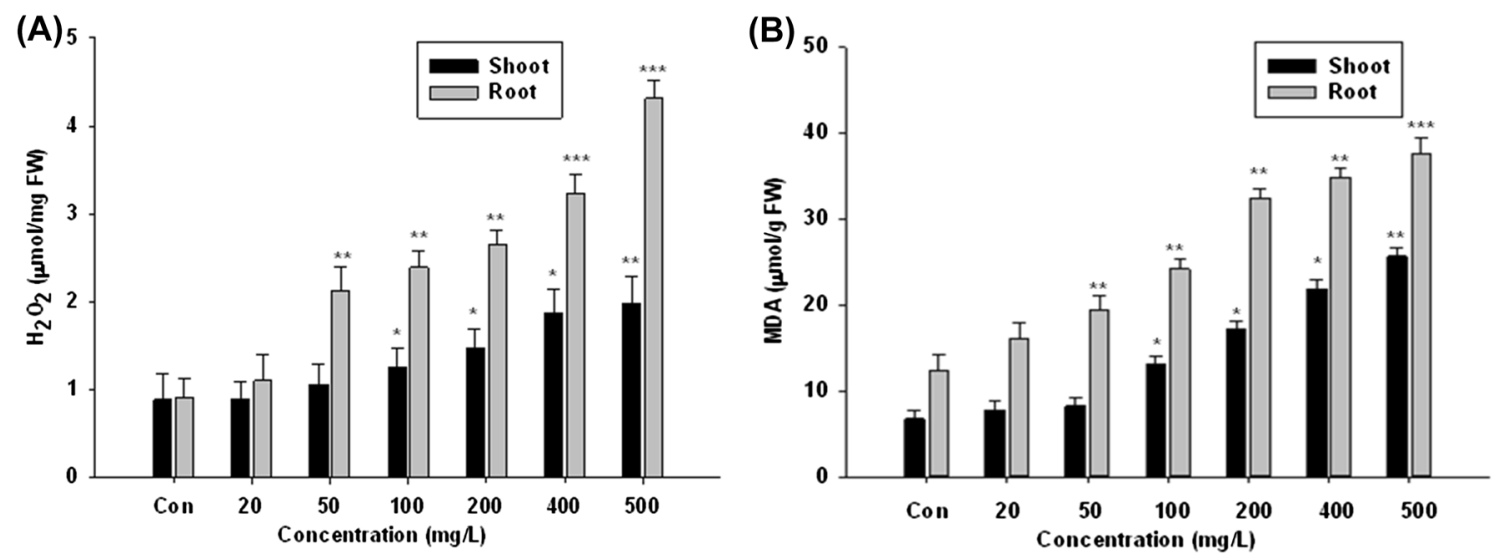

Fig. 3 a Hydrogen peroxide formation and $\mathbf{b}$ lipid peroxidation in shoots and roots of $B$. napus seedlings exposed to different concentrations of $\mathrm{CuO}$ NPs for 14 days. Data are mean \pm SE of

expression of $C A T$ gene did not change significantly after exposure to various concentrations of $\mathrm{CuO}$ NPs (Fig. 5b). The CAT gene showed no significant alteration in its expression levels in roots of seedlings exposed to 20,50, and $100 \mathrm{mg} / \mathrm{L}$ of $\mathrm{CuO}$ NPs (Fig. 5b). However, significant

three replications and asterisks indicate significant difference at $* p<0.05, * * p<0.01$, and $* * * p<0.001$ level

up-regulation of $C A T$ gene occurred in roots upon exposure to 200, 400, and $500 \mathrm{mg} / \mathrm{L}$ of $\mathrm{CuO}$ NPs (Fig. 5b). The APX gene showed no significant change in its expression in shoots and roots at any of the treatments (Fig. 5c). 
(A)
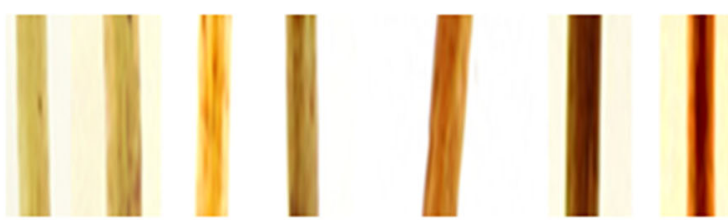

(B)

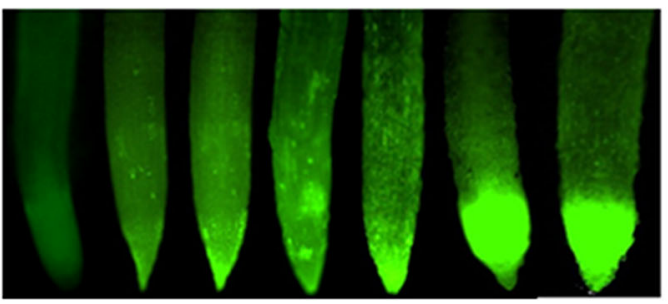

(C)

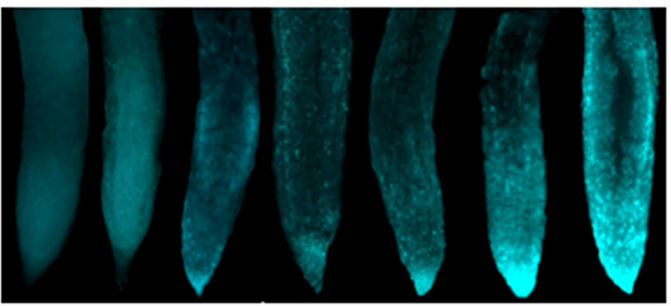

(D)

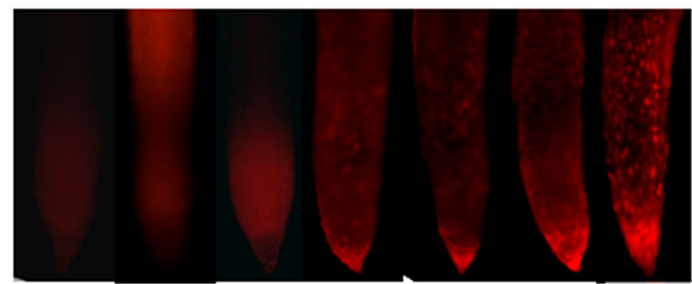

Fig. 4 a Histochemical detection of hydrogen peroxide formation in shoots. b Hydrogen peroxide formation in roots detected with $3^{\prime}-(p-$ hydroxyphenyl) fluorescein treatment. c Callose deposition in roots detected using aniline blue and $\mathbf{d}$ cytotoxicity assessment of roots using propidium iodide treatment. (In each panel from left to right; control and seedlings treated with 20, 50, 100, 200, 400, and $500 \mathrm{mg} /$ $\mathrm{L}$ of CuONPs, respectively)

\section{Discussion}

The rise in the production and usage of ENPs and their subsequent release and accumulation in the environment will have serious impacts on plant growth and development (Zhu et al. 2008). In our previous study, under the same growth conditions and exposure concentrations, alteration of root growth such as reduction in primary and lateral root growth was observed in B. juncea seedlings (Nair and Chung 2015). Exposure to CuO NPs led to changes in the root system architecture such as reduction in primary root growth as well as inhibition of lateral root growth in $B$. napus seedlings. As compared to B. juncea seedlings (Nair and Chung 2015), the toxic effects of CuO NPs on various parameters tested were more pronounced in B. napus seedlings, though the increased shoots and roots $\mathrm{Cu}$ contents of two species, as a result of $\mathrm{CuO}$ NPs exposure, were not very different (Nair and Chung 2015). Lateral root growth was observed even at the highest exposure concentration of $\mathrm{CuO}$ NPs in B. juncea seedlings (Nair and Chung 2015) as compared to complete inhibition in $B$. napus seedlings.

Lipid peroxidation serves as an indicator of the extent of oxidative damage under oxidative stress. It has been known that exposure to excess $\mathrm{Cu}$ could enhance the ROS generation which in turn cause peroxidative damage to membrane lipids (Dietz et al. 1999). In this study, the lipid peroxidation level showed significant increase in B. napus seedlings treated with $\mathrm{CuO}$ NPs. The presence of higher concentrations of $\mathrm{Cu}$, as revealed by the nutrient analysis, might have led to the increased lipid peroxidation levels in $B$. napus seedlings. Treatment with PI indicated cytotoxicity, in the root tips of B. napus seedlings treated with $\mathrm{CuO}$ NPs. As reported earlier as in the case of excess $\mathrm{Cu}$ (Feigl et al. 2013), the enhanced ROS generation as a result of the increased $\mathrm{Cu}$ levels under $\mathrm{CuO}$ NPs treatment caused the cytotoxicity in roots of B. napus seedlings.

In this study, inhibition of lateral root growth was observed after treatment with $\mathrm{CuO}$ NPs in B. napus seedlings. It was reported that loss of cell viability in root tips (in the meristem) could lead to the inhibition of root elongation in Brassica spp. (Feigl et al. 2013). Previous studies have shown that elongations of roots in plants are affected by the redox status in their apical region (CórdobaPedregosa et al. 2005). Changes in the redox status contribute to cell wall secondary thickening resulting in the reduction of cell growth and are negatively correlated with root elongation (Feigl et al. 2013). In this study, for the first time, we observed callose deposition as a result of $\mathrm{CuO}$ NPs exposure in roots of $B$. napus seedlings. It has been known from previous studies that $\mathrm{Cu}$ is an efficient inducer of callose formation in B. napus roots (Feigl et al. 2013). The callose deposition could inhibit cell wall loosening and thereby negatively affect root growth by inhibiting the passage of signal molecules or supply of carbon required for root growth in plants (Jones et al. 2006). Moreover, previous studies have shown that the disturbances in the auxin and cytokinin levels could also alter the primary and lateral root growth in plants (Aloni et al. 2006; Laplaze et al. 2007; Nibau et al. 2008). It has been reported that exposure to water soluble fullerenes caused abnormalities in hormone distribution resulting in the shortening of root growth in A. thaliana (Liu et al. 2010).

It was observed that exposure to $\mathrm{CuO}$ NPs significantly increased the ROS generation in B. napus seedlings. The presence of excess $\mathrm{Cu}$ content, as observed in micronutrient analysis, might have led to the excess ROS generation. The presence of excess $\mathrm{Cu}$ has been reported to cause dysfunction of the electron transport chain and thereby enhancing the ROS generation in plants. Plant cells have 

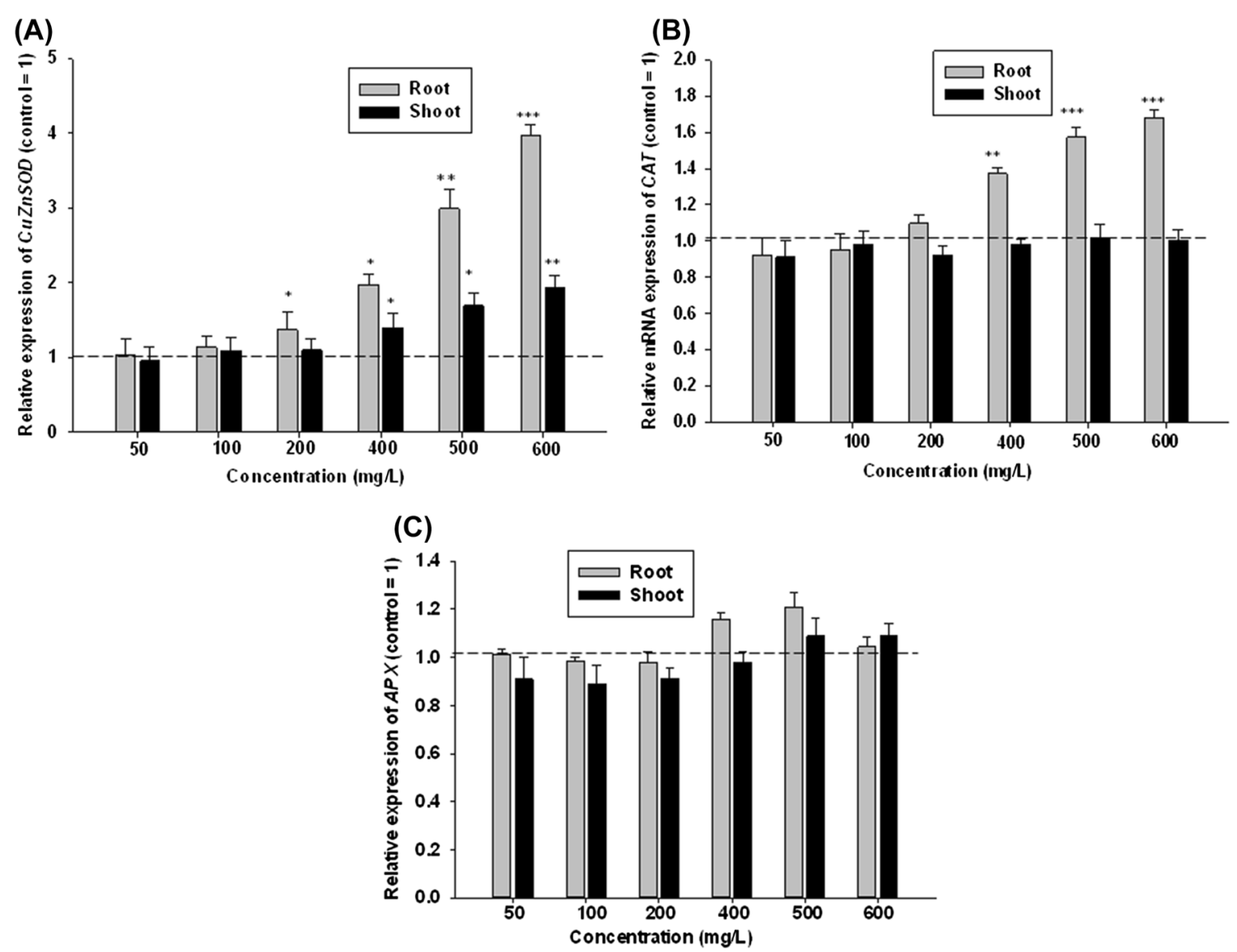

Fig. 5 Effect of different concentrations of $\mathrm{CuO}$ NPs on the expression of a $\mathrm{CuZn}$ superoxide dismutase $(\mathrm{CuZnSOD})$, b catalase $(C A T)$, and $\mathbf{c}$ ascorbate peroxidase $(A P X)$ genes in shoots and roots of B. napus seedlings after 14 days of exposure. Data are mean $\pm \mathrm{SE}$ of

evolved various antioxidant systems to cope with excess ROS generation (Sandmann and Boger 1980). It has been shown that increased ROS levels lead to the activation of genes coding for antioxidative enzymes such as CuZnSOD and CAT (Ezaki et al. 2000). The SODs accelerate the conversion of superoxides to $\mathrm{H}_{2} \mathrm{O}_{2}$ and CATs are involved in $\mathrm{H}_{2} \mathrm{O}_{2}$ breakdown (Bowler et al. 1992). APX has stronger substrate affinity than CAT and the induction of APX will be necessary for the efficient removal of $\mathrm{H}_{2} \mathrm{O}_{2}$ (Tripathi et al. 2006). In B. napus, we observed an increase in the expression levels of $C u Z n S O D$ and $C A T$ genes. However, no significant change in the expression of $A P X$ gene was observed. Therefore, the gene expression results indicate that there was an enhanced production and inadequate removal of ROS in B. napus seedlings treated with $\mathrm{CuO}$ NPs.

In the present study, for the first time, we observed that exposure to $\mathrm{CuO} \mathrm{NPs}$ has resulted in significant reduction in microelement content in B. napus seedlings. The possible reason for the observed reduction in microelements viz. $\mathrm{Zn}, \mathrm{Fe}$, and $\mathrm{Mn}$ in both shoots and roots of B. napus seedlings might be due to the competition in the uptake of three replications and asterisks indicate significant difference as compared to the control (control $=1)(* p<0.05, * * p<0.01$ and $* * * p<0.001)$

elements in the presence of excess $\mathrm{Cu}$ (Luo and Rimmer 1995; Lequeux et al. 2010). For example, in the case of $\mathrm{Zn}$ and $\mathrm{Fe}$, the $\mathrm{Cu}-\mathrm{Zn}$ antagonism or the competition of transport molecules might have resulted in the reduction in Zn level (Luo and Rimmer 1995; Feigl et al. 2013). The Mn deficiency might be due to the reducing effect of $\mathrm{Cu}$ on Mn leading to the reduced uptake of Mn (Feigl et al. 2013). Another reason for the observed changes might be due to the inhibition of water and nutrient uptake as a result of $\mathrm{CuO}$ NPs exposure. A previous study by Asli and Neumann (2009) showed that titanium dioxide nanoparticles interfered with the ability of maize by forming aggregates along the root cell walls.

\section{Conclusion}

In conclusion, it is observed that $\mathrm{CuO}$ NPs caused multilevel toxic effects on the growth and development of $B$. napus seedlings. Modification of root system architecture was observed due to $\mathrm{CuO}$ NPs exposure. Exposure to $\mathrm{CuO}$ NPs enriched the $\mathrm{Cu}$ content in the seedlings and decreased 
$\mathrm{Fe}, \mathrm{Zn}$, and $\mathrm{Mn}$ microelements. Moreover, excess ROS accumulation, especially in the root tips, was observed leading to lipid peroxidation and cell death. Callose formation was also observed in roots of $B$. napus seedlings exposed to $\mathrm{CuO}$ NPs. Further studies are required to understand the molecular mechanisms and the role of hormonal changes in root growth modification in B. napus as a result of $\mathrm{CuO}$ NPs exposure.

Acknowledgements This paper was supported by the KU Brain Pool Program of Konkuk University, Seoul, South Korea.

\section{Compliance with ethical standards}

Conflict of interest The authors declare that they have no conflict of interest in the publication.

\section{References}

Ali B, Qian P, Jin R, Ali S, Khan M, Aziz R, Tian T, Zhou W (2014) Physiological and ultra-structural changes in Brassica napus seedlings induced by cadmium stress. Biol Plant 58:131-138

Aloni R, Aloni E, Langhans M, Ullrich CI (2006) Role of cytokinin and auxin in shaping root architecture: regulating vascular differentiation, lateral root initiation, root apical dominance and root gravitropism. Ann Bot 97:883-893

Asli S, Neumann PM (2009) Colloidal suspensions of clay or titanium dioxide nanoparticles can inhibit leaf growth and transpiration via physical effects on root water transport. Plant Cell Environ 32:577-584

Bowler C, Van Montagu M, Inzé D (1992) Superoxide dismutase and stress tolerance. Annu Rev Plant Physiol Plant Mol Biol 43:83-116

Brennan T, Frenkel C (1977) Involvement of hydrogen peroxide in regulation of senescence in pear. Plant Physiol 59:411-416

Córdoba-Pedregosa MC, Córdoba F, Villalba JM, González-Reyes JM (2005) Changes in intracellular and apoplastic peroxidase activity, ascorbate redox status, and root elongation induced by enhanced ascorbate content in Allium cepa L. J Exp Bot 56:685-694

Das M, Saxena N, Dwivedi PD (2009) Emerging trends of nanoparticles application in food technology: safety paradigms. Nanotoxicol 3:10-18

Dietz KJ, Baier M, Kramer U (1999) Free radicals and reactive oxygen species as mediators of heavy metal toxicity in plants. In: Prasad MNV, Hagemeyer J (eds) Heavy metal stress in plants: from molecules to ecosystems. Springer, Berlin, pp 73-97

Ezaki B, Gardner RC, Ezaki Y, Matsumoto H (2000) Expression of aluminum-induced genes in transgenic Arabidopsis plants can ameliorate aluminum stress and/or oxidative stress. Plant Physiol 122:657-665

Feigl G, Kumar D, Lehotai N, Tugyi N, Molnár A, Ördög A, Szepesi A, Gémes K, Laskay G, Erdei L, Kolbert Z (2013) Physiological and morphological responses of the root system of Indian mustard (Brassica juncea L. Czern.) and rape seed (Brassica napus L.) to copper stress. Ecotoxicol Environ Saf 94:179-189

Gardea-Torresdey JL, Rico CM, White JC (2014) Trophic transfer, transformation, and impact of engineered nanomaterials in terrestrial environments. Environ Sci Technol 48:2526-2540

Gill RA, Hu XQ, Ali B, Yang C, Shou JY, Wu YY, Zhou WJ (2014) Genotypic variation of the responses to chromium toxicity in four oilseed rape cultivars. Biol Plant 58:539-550
Heath RL, Packer L (1968) Photoperoxidation in isolated chloroplasts. I. Kinetics and stoichiometry of fatty acid peroxidation. Arch Biochem Biophys 125:189-198

Horst WJ, Püschel AK, Schmohl N (1997) Induction of callose formation is a sensitive marker for genotypic aluminum sensitivity in maize. Plant Soil 192:23-30

Jones D, Blancaflor E, Kochian L, Gilroy S (2006) Spatial coordination of aluminium uptake, production of reactive oxygen species, callose production and wall rigidification in maize roots. Plant Cell Environ 29:1309-1318

Kwasniewski M, Chwialkowska K, Kwasniewska J, Kusak J, Siwinski K, Szarejko I (2013) Accumulation of peroxidase related reactive oxygen species in trichoblasts correlates with root hair initiation in barley. J Plant Physiol 170:185-195

Kwon YI, Abe K, Endo M, Osakabe K, Ohtsuki N, Nishizawa-Yoko A, Tagiri A, Saika H, Toki S (2013) DNA replication arrest leads to enhanced homologous recombination and cell death in meristems of rice OsRecQ14 mutants. BMC Plant Biol 13:62-75

Laplaze L, Benkova E, Casimiro I, Maes L, Vanneste S, Swarup R, Weijers D, Calvo V, Parizot B, Herrera-Rodriguez MB, Offringa R, Graham N, Doumas P, Friml J, Bogusz D, Beeckman T, Bennett M (2007) Cytokinins act directly on lateral root founder cells to inhibit root initiation. Plant Cell 19:3889-3900

Lequeux H, Hermans C, Lutts S, Nathalie V (2010) Response to copper excess in Arabidopsis thaliana: impact on the root system architecture, hormone distribution, lignin accumulation and mineral profile. Plant Physiol Biochem 48:673-682

Liu Q, Zhao Y, Wan Y, Zheng J, Zhang X, Wang C, Fang X, Lin J (2010) Study of the inhibitory effect of water-soluble fullerenes on plant growth at the cellular level. ACS Nano 4:5743-5748

Luo Y, Rimmer DL (1995) Zinc-copper interaction affecting plant growth on a metal contaminated soil. Environ Poll 88:79-83

Nair PMG, Chung IM (2015) Study on the correlation between copper oxide nanoparticles induced growth suppression and enhanced lignification in Indian mustard (Brassica juncea L.). Ecotoxicol Environ Saf 113:302-313

Navarro E, Baun A, Behra R, Hartmann NB, Filser J, Miao AJ, Quigg A, Santschi PH, Sigg L (2008) Environmental behavior and ecotoxicity of engineered nanoparticles to algae, plants and fungi. Ecotoxicol 17:372-386

Nibau C, Gibbs DJ, Coates JC (2008) Branching out in new directions: the control of root architecture by lateral root formation. New Phytol 179:595-614

Sandmann G, Boger P (1980) Copper-mediated lipid peroxidation processes in photosynthetic membranes. Plant Physiol 66:797-800

Schützendübel A, Polle A (2002) Plant responses to abiotic stresses: heavy metal-induced oxidative stress and protection by mycorrhization. J Exp Bot 53:1351-1365

Shahandeh H, Hossner LR (2002) Plant screening for chromium phytoremediation. Int J Phytoremediation 2:31-51

Thordal-Christensen H, Zhang Z, Wei Y, Collinge DB (1997) Subcellular localization of $\mathrm{H}_{2} \mathrm{O}_{2}$ in plants: $\mathrm{H}_{2} \mathrm{O}_{2}$ accumulation in papillae and hypersensitive response during the barley-powdery mildew interaction. Plant J 11:1187-1194

Tripathi BN, Mehta SK, Amar A, Gaur JP (2006) Oxidative stress in Scenedesmus sp. during short- and long-term exposure to $\mathrm{Cu}$ and Zn. Chemosphere 62:538-544

Wang Z, Xie X, Zhao J, Liu X, Feng W, White JC, Xing B (2012) Xylem and phloem based transport of $\mathrm{CuO}$ nanoparticles in maize (Zea mays L.). Environ Sci Technol 46:4434-4441

Yruela I (2005) Copper in plants. Braz J Plant Physiol 17:145-156

Yruela I (2009) Copper in plants: acquisition, transport and interactions. Funct Plant Biol 36:409-430

Zhu H, Han J, Xiao JQ, Jin Y (2008) Uptake, translocation, and accumulation of manufactured iron oxide nanoparticles by pumpkin plants. J Environ Monit 10:713-717 